BPMJ

5,1

50

\title{
Mapping customers' service experience for operations improvement
}

\author{
Mitchell M. Tseng, Ma Qinhai and Chuan-Jun Su \\ Hong Kong University of Science and Technology, Hong Kong
}

Keywords Customers, Improvement, Operations, Service

Abstract The growing importance of the service sector in almost every economy in the world has created a significant amount of interest in service operations. In practice, many service sectors have sought and made use of various enhancement programs to improve their operations and performance in an attempt to hold competitive success. As most researchers recognize, service operations link with customers. The customers as participants act in the service operations system driven by the goal of sufficing his/her added values. This is one of the distinctive features of service production and consumption. In the paper, first, we propose the idea of service operations improvement by mapping objectively the service experience of customers from the view of customer journey. Second, a portraying scheme of service experience of customers based on the IDEF3 technique is proposed, and last, some implications on service operations improvement are given.

\section{Introduction}

We first introduce our basic concept of service experience of customers starting with the simplified conceptual model of service operations systems (Figure 1) which is modified based on the servuction system model adopted by Bateson (1995).

As the model implies, service operations link with customers. Customers as participants act or behave in the service operations system driven by the goal of sufficing their added values. The active participation of customers is one of the unique characteristics of service operations that set a service operations system apart from manufacturing systems. The service operations are divided into two parts - that which contacts with customers and that which does not. In turn, the customer contact part is broken into two portions - the inanimate environment and the service personnel. The service value (benefit) perceptions of customers are achieved in the contacts between customers and the contact personnel who are responsible for certain operation tasks and/or the inanimate environments which function for the customers. The totality that customers experience is called the service experience of customers with respect to a service operations system. Customers' service experience relays how service contacts actually occur. Thus, it was proposed that when a customer purchases a service, he or she purchases an experience created in the service operations of a service organization (Bateson, 1995).

The growing importance of the service sector in almost every economy in

Business Process Management Journal, Vol. 5 No. 1, 1999, pp. 50-64. (C) MCB University Press, 1463-7154 the world has created a significant amount of interest in service operations. In practice, many service sectors have sought and made use of various 
enhancement programs to improve their operations performance in an attempt to hold competitive success. Competitive success of an organization ultimately depends on customer satisfaction, which is then determined critically by their experience which the service operations are able to maintain. Market research has shown that customers dissatisfied with a service will divulge their experience to more than three people (Horovitz, 1990). Poor service experience of customers will reduce the potential customer base of an organization and in turn has an adverse impact on the organization's performance. A negative service experience of customers not only forces the existing customers to migrate to competitors but also, due to the effect of negative word of mouth, results in fruitless effort of the organization to attract new customers. The purpose of this paper is to share our research findings on service operations improvement by organizations to maintain satisfactory service experience of customers. First, we propose the idea of service operations improvement by mapping objectively the service experience of customers from the view of customers' journey. Second, a portraying scheme of service experience of customers based on the IDEF3 technique is proposed, and last, some implications on the service operations improvement are given.

\section{Service operations improvement}

\section{Literature review}

It is commonly accepted that customer satisfaction is a critical indicator reflecting the health of service operations. The more satisfied customers feel about their experience in the service operations system, the more competitiveness the system possesses. The increasing attention on customers' service experience as a way to help improve service operations (effectiveness) is evident in the body of literature.

Shostack (1984) noticed that examples of poor service were widespread, and stated that faced with service problems one tended to become somewhat paranoid; no one systematically qualified the process or devised any type of tests to ensure that service is complete, rational, and fulfills the customer's needs objectively. For these issues, she developed a service blueprint scheme which does provide the useful tool for describing visually the concept of service operations. It is especially appreciated that the service blueprint highlights the customer interactions in the service operations processes and, that the line of

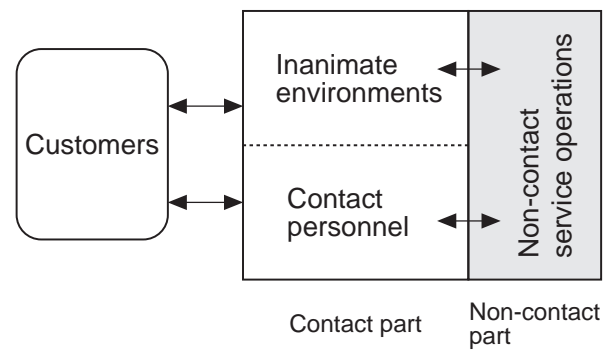

Mapping service experience

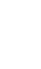


BPMJ

5,1 visibility is used to separate activities of the front office, where customers obtain tangible evidence of the service, from the back office processing, which is out of customer view. The blueprint can facilitate problem solving and create thinking by identifying potential points of failure and highlighting opportunities to enhance customers' perceptions of the service.

Sulek et al. (1995) reported an empirical study on the impact of a customer service intervention and facility design on firm performance within a regional food retailing chain. The result of the study indicated, in the research context, that the improvement in the customer experience could leverage positively customer satisfaction and firm performance. Danaher and Mattsson (1994) studied customer satisfaction evaluation on a hotel conference service delivery process. The focus is on how underlying quality factors are related to different service encounters (different service experience stages) of the entire service experience and how cumulative customer satisfaction levels impact on each other and over time.

The customer-employee interactions are an important side of the service experience of customers which can have a significant impact on both customer satisfaction and organization performance. Czepiel (1990) viewed several discussions on service encounters and stated the social view of the encounter between the service provider and customer: "Service encounters are characterized by their purposiveness, the motivation of the provider, and their ability to allow strangers to interact in a way that transcends the barriers of social status. They are limited in scope and have well-defined roles for participants in which task-related information exchange dominates." Good service encounters accumulated over time maintain a long-term exchange relationship between customers and organization. Researchers (Schneider and Bowen, 1993; Kelley, 1993; Bitran and Hoech, 1990) explored the issue of improving the interaction through human resources management. As Bitran and Hoech (1990) hold, to a large extent, firms can assure quality in high contact service settings by training and motivating frontline employees to treat customers respectfully. They discussed the issue of communication, control, empowerment, and respect in an integrated way for the purpose of achieving more effective service operations. Lockwood and Jones (1989) formulated interactive variables of both parties (providers and customers) involved in service encounters as: personal characteristics, perceptions of each other, social competence, and needs and objectives. The socio-psychological features of customer-provider encounters were analyzed. The authors addressed common difficulties that service providers encounter in fulfilling their roles. These difficulties include: role ambiguity, role conflict, role overload, role incompatibility, and multi-role conflict. Right actions for improving service encounters were proposed in their work: using scripts for both participants of the encounter to recognize and formalize the provider's behavior and orient the customer's expectation, altering the service operations system and stressing the organization culture. 
The impact of physical surroundings on customers was explored by Bitner (1992). In the work, a framework for understanding the physical environmentuser relationships in service organizations was proposed and 18 focused propositions were made. For instance, "Customers and employees perceive the environment holistically, as a composite of some dimensions: ambient conditions; spatial layout; and functionality; signs, symbols, and artifact. Each dimension may affect the overall perception independently and/or through its interactions with the other dimensions."

Katz et al. (1991) examined customers' perceptions of the waiting experience in an empirical way based on banking operations. They summarized major findings of the work: the average overestimate customers made on their waiting time is about one minute, and waits of five minutes or less are considered reasonable; as perceptions of waiting time increase, customer satisfaction tends to decrease; increased distractions make the waiting experience more interesting and tend to increase customer satisfaction; information on expected time in queue tends to improve the accuracy of customer perceptions of waiting but does not influence customer satisfaction. Accordingly the researchers formulated several suggestions for managers to improve service operations focusing on customer waiting experience, such as "to install distractions that entertain and physically involve the customer". Carmon et al. (1995) illustrated some aspects of the psychological cost of customer waiting using an analytical queuing model and suggested that service should be scheduled in a manner that not only considered time spent in the system, but also considered customers' (dis)satisfaction.

There are many explorations into the service quality subject (Mills, 1990; Oliver, 1993; Ghobadian et al., 1994; Zeithaml et al., 1993; Stafford, 1994) almost all of which are service experience concerned. Parasuraman et al. (1988) proposes the determinants of service quality: reliability, responsiveness, assurance, empathy, and tangibles. Haywood-Farmer (1988) suggests that there are aspects of professional service quality: physical facilities; processes and procedures; people's behavior and conviviality; and professional judgment. These are all service experience related factors.

\section{Thoughts on service operations improvement}

Related research efforts reviewed previously have made a great contribution to both academic explorations and practical applications in service operations improvement. However, service operations have so far not been adequately studied through a systematic portrayal of the entire service experience of customers in accordance with the customer's activities. Although the service blueprint scheme (Shostack, 1984) heeds the customer interaction, it is still the conventional work-flow concept dominated flowchart, not focusing on the complete picture of customers' service experience, and hence does not place stress on uncovering the problems behind the service operations through investigation of customers' service experience. Moreover, this scheme reveals the inability of detailing information about customers' service experience. 
BPMJ

5,1
This paper will take an initial step toward filling this gap by absorbing prior research achievements. As the basis of the idea of service operations improvement by mapping customers' service experience, three propositions are stated.

Proposition 1: Customer-oriented management philosophy is the key to the competitive advantage of organizations. Customer-oriented management philosophy maintains the notion that management ought to consider customers when determining what improvements are needed. That is, the managerial actions should be taken from customers' view points. Arguments in favor of customer-oriented managing are persuasive. Maintaining customer satisfaction and sufficing customer value have been increasingly identified as an important and effective way for businesses to gain competitive advantage. Repeat business from satisfied customers generates long-term revenue that is key to profitability (Kingman-Brundage et al., 1995). More outward orientation toward customers becomes a major source for organization's competitive advantage. There are no shortages of call for organizations to orient strategy toward superior customer value, and organized evidence to support the management philosophy (Woodruff, 1997).

In the context of service operations, the management philosophy can be translated as: operations management decisions should be oriented toward customers' service experience where customers judge service quality and perceive value.

Proposition 2: The problems that erode the customer value, and the improvement opportunity that enhances the customer value can be discovered through auditing the service experience of customers. The reason why customers experience a service operations system is that they consider it represents some value they are looking for. In customers' eyes, service experience is perceived as the service product produced by the service operations system. Through experiencing the service operations system, customers make judgments about what they perceive and consequently have service value perception (positive or negative). For customers, their value perception is the direct function of their service experience, that is, the customer value perception is directly determined by their service experience. The service experience either adds or subtracts value in customers' eyes; their satisfaction or dissatisfaction (if any) comes from their perception of what they experienced.

For example, customers usually have contact with the service personnel, the communication with a teller in a banking service for example, for their needs in the service operations system; the problem of incongruous interaction may appear corresponding to the point of service experience of customers. As part of the service experience of customers, customer waiting usually takes place at the site of the service operations system. In that case, the improvement potentials, such as preparing an espresso machine or water supply, free telephone and readings in favor of customers, become necessary accordingly. So, effective analysis of the service experience of customers is a critical source for improving service operations. 
Proposition 3: The service experience of customers is describable. One may argue that the psychology and behavior of customers vary considerably, and the service experience of customers with respect to a service operations system is customer-unique. Accordingly the service experience of customers is not describable or at least difficult to describe. Indeed, this logic falls in the "fallacy of completeness" and ignores the abstraction ability of humans. Here, this proposition follows the context below.

It is evident that when people behave in a certain environment or with certain relationships, certain experience is created. The environment or relationships created by the system shape all the customer-unique service experiences thus giving them common characteristics with respect to a service operations system. So, according to the service operations system (its operation processes, policies and regulations, physical environment and others) and the observed customer behavior, we can get a description of the service experience of customers, the comprehensive abstraction of all the instances of the customer-unique service experience. Fortunately, we humans have the ability to model the real world. Modeling has been a useful and widely adopted tool for analyzing and improving (even optimizing) the real situations. It is a way to abstract something for the purpose of understanding it before improving it. Because a model omits nonessential details, it is easier to manipulate than the real situation.

The idea of service operations improvement by the service experience of customers follows the above propositions and is stated as: we can improve service operations through uncovering the service experience of customers by following the customer's experience mapping. In other words, we expect to get useful insight into service operations improvement, such as disclosing where the service operations should be improved so that the customer value perception can be enhanced, by examining systematically how customers behave, what they come in contact with, and what their journey is regarding the existing service operations system. This idea is illustrated in Figure 2.

\section{Portraying service experience of customers}

\section{General idea}

In this section, we introduce the scheme to portray the customer experience so that the entire service experience of customers can be presented.

A widely accepted systems engineering technique, IDEF3 (Plaia and Carrie, 1994; $\mathrm{Su}, 1996)$, provides a supporting tool for this purpose. IDEF3 is a process mapping technique based on combining graphics and text that are then presented in an organized and systematic way to be understood to support

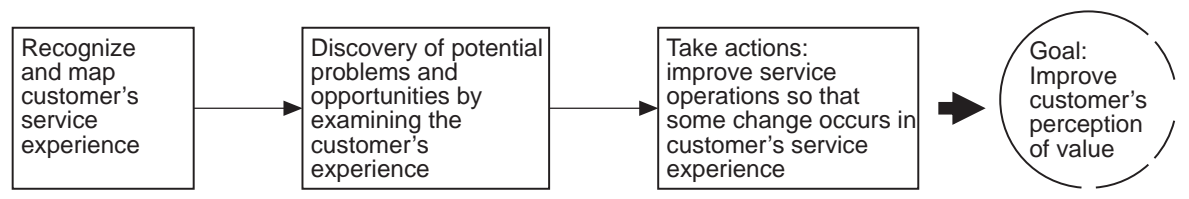

Figure 2.

Service operations improvement 
BPMJ

5,1

56 analysis, provide logic for potential changes, specify requirements, or support systems-level design and integration activities. An IDEF3 process flow description (process map) consists of a set of process flow diagrams and complete elaboration documents which provide us with a method to model the real world.

With abstraction and generalization, we can define a set of customer behavior units corresponding to customer behaviors involved in the service experience. For example, regarding the service experience of customers in a supermarket, we can define a customer behavior unit identified by "check out", which describes a customer's behavior starting from queuing, to paying, and finally to leaving. The connection of all the behavior units defined in their possible sequence forms a customer behavior network which describes the customer behavior states and their transition. In this scheme, we adopt the IDEF3 process flow description diagram to represent the customer behavior network. A UOB (unit of behavior) box is assigned to present a customer behavior unit (CBU). The agent of a CBU is the customer who participates in the service operations system. The customer behavior network by IDEF3 process flow diagram represents all possible modes of customer behavior for approaching a particular customer's aim.

The IDEF3 process flow description diagram representing the customer behavior network models the customer experience with CBUs using verb-noun combinations. However, cursory description alone will not provide a complete picture of the customer experience. Critical to the full understanding of the customer experience is the elaboration of each CBU. Correspondingly, the elaboration document is used to describe the details of each CBU.

The description from the two aspects constitutes the model of service experience of customers.

\section{Getting started}

The customer behavior network portrays the important possible customer's behavior cases with respect to the service operations system under analysis. It is the abstraction of the behaviors of all customers who experience the system in terms of common behavior features. To draw the network, the "how question" (how do customers act or behave?) and "what question" (what customer actions or behaviors are involved) should first be asked aiming at the entire life circle of customers' service experience from customers' entering the system to their leaving it.

The description starts with a simple diagram that summarizes the general CBUs at a higher level of abstraction because, in general, we can not go into details at once due to the limitations of human capacity for dealing with complexity. An identical name and reference number are given to each of the defined CBUs by using verb-noun combination and number. Figure 3 is an example which shows, at higher level of abstraction, the customer behavior network with respect to a supermarket shop. The diagram follows the IDEF3 process flow diagram language. 
The boxes show the CBUs. The solid arrows are used as precedence links expressing the order in which two connected CBUs occur. If two CBUs are connected by a precedence link, an instance of the first enables an instance of the second.

\section{Elaboration document}

After finishing one level of $\mathrm{CBU}$ definition, the elaboration corresponding to each $\mathrm{CBU}$ should be made. The elaboration for each $\mathrm{CBU}$ is presented in the form of a document as shown in Figure 4. The elaboration document describes the facts relating to each CBU. As listed in Figure 4, five elements are focused on.

- Customer contact object: While customers experience the service operations system, they must make contact with the elements of the system, through which customers have value perceptions of the service they use. We use customer contact objects to portray the things customers make contact with regarding the CBU defined. Therefore we define a customer contact object as an identifiable entity, either real or abstract, which is perceptible to customers when they play their role in the system. Customer contact objects are the operational elements that effect the customer's service value perception. These objects can be service facilities, employees, service operational units, or whatever by principle is perceptible to customers.

This part of the elaboration document lists the names of all defined customer contact objects associated with the CBU indicated at the top.

- Attributes of the customer contact object: They describe the characteristics of the defined customer contact object and denote the

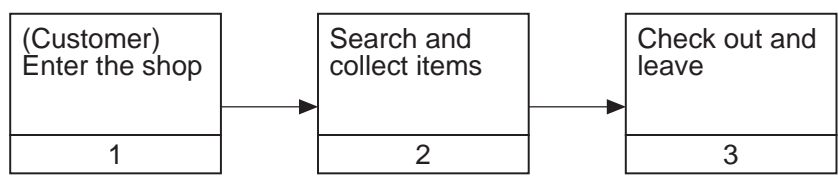

\begin{tabular}{l} 
Elaboration Document Ref. No. \\
CBU Name: \\
CBU Label: \\
\hline Customer contact object: \\
Attributes of the customer \\
contact object: \\
Operations of the customer \\
contact object: \\
Relationships between \\
the object and customer:
\end{tabular}

Mapping service experience

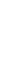


BPMJ

5,1

\section{8}

static properties the object possesses. For example, we define "Check-out station" as a customer contact object related to the CBU "Check out" and its attributes as "layout style", "area occupied", "location", "customer payment ways".

- Operations of the customer contact object: This segment is to characterize the customer contact objects listed above from their dynamic (behavior) aspects. Operations of a customer contact object are functions or transformation that may be applied to or by customers or other elements of the service operations system. They refer to the processing units of a customer contact object that can be requested. To carry out this part of the document, one should examine what operations an object performs first for customers, and then for others. For example, the customer contact object, "Check-out station" performs an operation "receive payment".

- Relationships between the object and customer: There are relationships between customers and a customer contact object. This part is to map these relationships. The relationships can be captured from different perspectives. In this research we assert that the relationships are described from the following thinking context.

- What operations are carried out on a customer contact object by customers as operators?

- What are the effects which the customer contact object has on customers (such as the information and physical goods passed onto, or some assistance provided for customers)?

- What is requested of customers from the customer contact object?

For example, we describe the relationship between the customer contact object, "Check-out station", and customers, as shown in graph (Figure 5).

If, however, a CBU is so comprehensive that its elaboration is difficult, the elaboration document associated with the CBU may consist of only a general description of the contents of each field listed above.

\section{Decomposition}

If a CBU is so highly complex that a satisfactory portrayal of customers' service experience is not reached, it is necessary to decompose it into sub-CBUs that form a sub-customer behavior network. This "exploded" description, one level less in the abstraction of details, allows a more specific elaboration of that CBU. That is, the decomposition allows for the capture of descriptions at

Figure 5.

Representation of relationships between customer contact object and customers

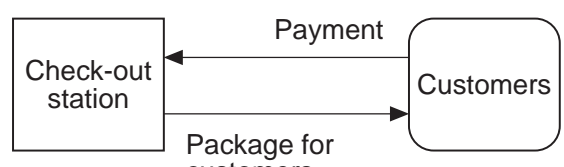

customers 
varying levels of abstraction. Decomposition enables the application of the "divide and conquer" principle, a powerful mechanism for managing complexity. By applying this principle repeatedly, it is possible to specify the customer's service experience to any level of details required. The representation of the decomposition of a CBU can take the format as shown in Figure 6.

For example, what sub-customer-behavior network does the CBU "Search and collect items" in Figure 3 decompose into? To answer the question, we perform the decomposition as shown in Figure 7.

How do we know what the sub-customer-behavior network is made up of? The decomposition is accomplished based on the following:

- the modeler's consciousness of the concept of up-level CBUs;

- the modeler's skill to deal with complexity;

- information-gathering approaches: interviewing employees who are experienced in the "front-office" of the service operations system; observing how customers behave; experiencing what the customer experiences.

Once the decomposition of up-level CBUs into lower components has been accomplished, the elaboration is performed for newly defined CBUs. Each of the newly defined CBUs may be decomposed into a more detailed sub-customer behavior network and the corresponding elaboration is carried out in turn. Through certain iterations of the like of decomposition-elaboration, we can arrive at a satisfactory picture of the customer's service experience.

\section{Use of junction and referent}

IDEF3 suggests ten types of junctions that are defined in three-dimensional natures: logical semantics (AND (\&), OR (O), and exclusive OR (X)), convergence or divergence of multiple process paths (fan-in or fan-out), and the coordination of timing of the associated behavior units (synchronous or asynchronous).

The junctions that will be used in the case of mapping customer service experience are:

(1) Fan-out asynchronous \&: All the process paths leading out of the junction will eventually initiate in any order.

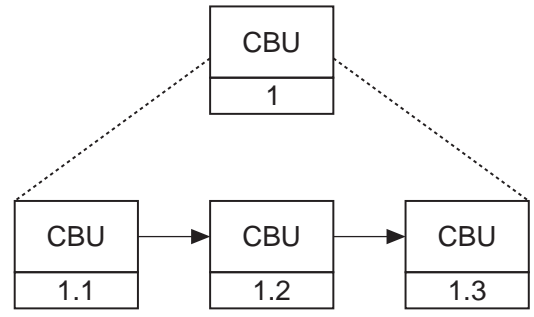

Figure 6. Decomposition concept 


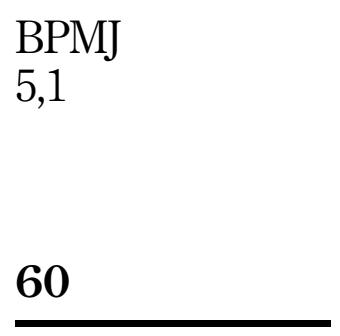

Figure 7.

Decomposition of $\mathrm{CBU}-$ search and collect items

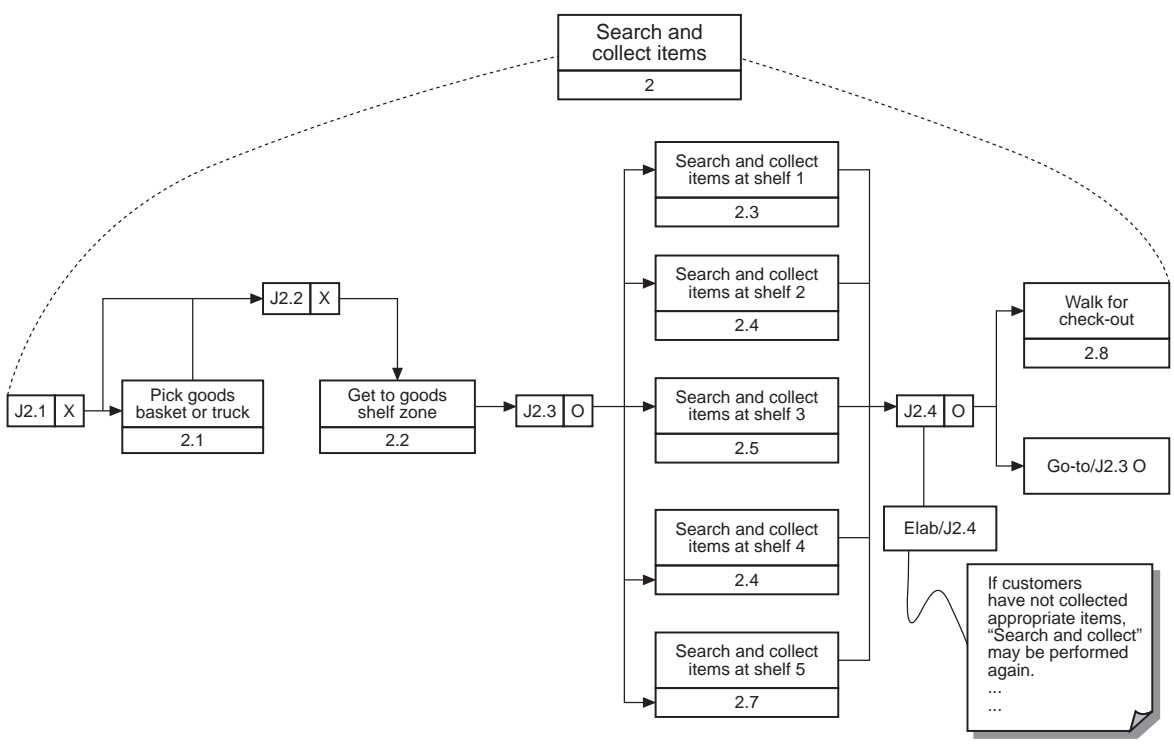

(2) Fan-out asynchronous $O$ : One or more of the process paths leading out of the junction will initiate in any order.

(3) Fan-out X: Only one of the process paths leading out of the junction will initiate.

(4) Fan-in asynchronous \&: All the process paths leading into the junction will complete, but not necessarily with any particular order or timing.

(5) Fan-in asynchronous $O$ : One or more of the process paths leading into the junction will complete, but not necessarily with any particular order or timing.

(6) Fan-in X: Only one of the process paths leading into the junction will complete.

For example, the use of fan-out and fan-in asynchronous $\mathrm{O}$ junction. In describing the customer's service experience in a service operations system, this situation may happen: one or more CBUs may take place following the same precedence $\mathrm{CBU}$ in a particular customer experience scenario toward a customer's aim. To cope with this case in drawing customer behavior network by IDEF3 process diagram, fan-out and fan-in asynchronous $\mathrm{O}$ junction can be adopted. As J2.3 and J2.4 express in Figure 7, after the CBU ("get to goods shelf zone") happens, some of CBUs ( "search and collect items at shelf 1 to 5") may initiate and complete in any order.

Two types of referents are suggested. One is elaboration referent (Elab) and another is Go-to referent. "Elab" referent is attached to a junction if necessary to express the conditions or constraints and other necessary facts about how the process paths diverge or converge at a fan-out or fan-in junction. This 
referent is shown in Figure 8 (a), where "Elab" indicates that the referent type is an elaboration referent, and ID must be the reference number of a junction, to which the referent is attached. "Elab/J2.4" shown in Figure 7 is an example. A Go-to referent is used to show the possibility of customers' activities looping back to the point the referent designates. The graphical symbol of Go-to referent is displayed basically in Figure 8 (b), where "Go-to" indicates that the referent type is a Go-to referent, and ID indicates the point to loop back to, which can be the reference number of a junction or the name of a CBU. If the ID is a junction reference number, the Go-to referent indicates that the next happening will be an occurrence of the $\mathrm{CBU}$ (s) following the referenced junction; if the ID is the name of a $\mathrm{CBU}$, the next happing will be an occurrence of the $\mathrm{CBU}(\mathrm{s})$ from the referenced CBU. For instance, in a supermarket, some customers may look for and collect items from one goods shelf to another several times repeatedly. As illustrated in Figure 7, the referent "Go-to/J2.3 O" is used to portray the situation.

\section{Implications for service operations improvement}

Organizations setting out to win customers, deliver good service, and survive vigorous competition have to engage in continuous improvement. Service operations improvement through mapping service experience of customers offers an alternative orientation toward and an operational tool for operations improvement for service organizations that follow the customer-oriented management philosophy.

For a systematic understanding of the customer's entire value addition chain, the customer's service experience by the proposed portraying scheme can offer adequate information from the customer's perspective for capturing improvement opportunity. A service experience portrayal provides the service organization with a complete recognition of what its "product" is. It allows an organization to test its service concept on paper and thoroughly work out the bugs.

Customers often have expectations about their service experience based on their value consideration and cumulative life experience or knowledge. Such expectations are often vague. But when customers come face to face with the reality, they always find themselves with a perception of how they can be satisfied regarding their journey, contacts they make in the service operations system, and the effect of contact objects on them. The analysis of the customer behavior network which reveals the reality of customer behavior journeys reminds us to raise the question: "Does it satisfy customers' expectations?". To obtain a solution, the following activities should be carried out consequently: question the necessity of each $\mathrm{CBU}$ from the customer's perspective, check

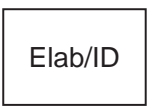

(a)

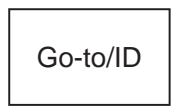

(b)
Mapping service experience

61

\section{$+$}


BPMJ

5,1

62

whether there are CBUs that customers are not willing to have, capture such customer tracks that are considered exceptions or unexpected (in this respect, ask why this situation to clarify whether or not customers are right or those involved CBUs should be restricted, and establish the way to deal with the situation), and determine whether some changes in the network can be made through generating new CBUs in favor of customers. A CBU elaboration document will facilitate and enhance the operations improvement program if it looks into questions like: "Are there customer contact objects which erode customer value?", "Are some CBUs needed to be modified so that customer value perception can be enhanced?", and "Is it feasible to create new customer contact objects corresponding to a CBU for improving customers' value perception?" For example, when customers participate in a service operations system, they always want to know the rules, guide, and orientation for their service experience. Through close and careful scrutiny, we try to find out whether there exists the situation that this kind of customer contact object is required but in fact neglected. In a supermarket, customer contact objects (goods shelves for example) illustrate physical goods to customers. For this kind of contact object, the management should always keep the question in mind: "Are there items about which customers feel satisfied?"

In order to identify potential areas for change, it is necessary for the service operations management to capture and anticipate what customers want or need. The portrayal of service experience of customers can assist management in this respect. For each $\mathrm{CBU}$, we recommend that the management should try to anticipate as many potential customer wants or needs as possible based on its elaboration document. After this effort, a customer wants or needs network can be figured out. This network is a valuable property of organization as it shows where improvements are needed in the service operations system and how such improvements ought to be made. The customer wants the network to provide the management with an operations improvement referent. The combination of this network and the portrayal of service experience of customers helps the management to carry out systematic and periodical inspections and remove operations that will cause poor service experience for customers. This practice would be particularly effective for customer-facility contact dominated service operations.

Danaher and Mattsson (1994) were among the first to look at customer cumulative satisfaction measurement, attempting to discover the service quality factors from the micro-customer processes. That study concludes that the result of the impact of different customer process stages on the overall customer satisfaction is of high managerial value for clarifying key (core) improvement orientation. The portrayal of the service experience of customers is a preliminary step toward this kind of research. With a good portrayal of customers' service experience, research along these lines can be conducted more effectively.

Some benefits may be brought forth by employees' participation. Organizations can involve their employees in the program, including portraying customers' 
service experience and creating operations improvement ideas. As a bridge, employees' participation encourages everyone to offer operations improvement suggestions from the customer's view point, and it makes the customer-oriented propaganda even more concrete for employees. The portrayal of customers' service experience may be used in employee training as a tool for helping employees understand systematically how the customer associates with their efforts, from the customer's perspective, and enable them to see beyond their own narrow job domain. As such, thanks to the elaboration document mechanism based on customer contact objects description, employees may acquire a better knowledge of the details that directly affect customer value perception and satisfaction, which may in turn enhance employees' consciousness concerning customer service.

\section{Reference}

Bateson, J.E. (1995), Managing Service Marketing, The Dryden Press, Harcourt Brace College Publisher, Hinsdale, IL.

Bitner, M. J. (1992), "Servicescapes: the impact of physical surroundings on customers and employees”, Journal of Marketing, Vol. 56 No. 2, pp. 57-71.

Bitran, G.R. and Hoech, J. (1990), "The humanization of service: respect at the moment of truth", Sloan Management Review, Vol. 31 No. 2, pp. 89-96.

Carmon, Z., Shanthikumar, J.G. and Carmon, T.F. (1995), “A psychological perspective on service segmentation model: the significance of accounting for consumers' perceptions of waiting and service”, Management Science, Vol. 41 No. 11, pp. 1806-15.

Czepiel, J.A. (1990), "Service encounters and service relationships: implications for research", Journal of Business Research, Vol. 20 No. 1, pp. 13-21.

Danaher, P. J. and Mattsson J. (1994), "Cumulative encounter satisfaction in the hotel conference process”, International Journal of Service Industry Management, Vol. 5 No. 4, pp. 69-80.

Ghobadian, A., Speller, S. and Jones, M. (1994), "Service quality: concepts and models", International Journal of Quality and Reliability Management, Vol. 11 No. 9, pp. 43-66.

Haywood-Farmer, J. (1988), “A conceptual model of service quality”, International Journal of Operations and Production Management, Vol. 8 No. 6, pp. 19-29.

Horovitz, J. (1990), How to Win Customers - Using Customer Service for a Competitive Edge, Longman, Harlow.

Katz, K.L., Larson, B.M. and Larson, R.C. (1991), "Prescription for the waiting-in-line blues: entertain, enlighten, and engage”, Sloan Management Review, Vol. 32 No. 2, pp. 44-53.

Kelley, S.W. (1993), "Discretion and the service employee”, Journal of Retailing, Vol. 69 No. 1, pp. 104-26.

Kingman-Brundage, J., George, W. and Bowen, D. (1995), "Service logic: achieving service system integration”, International Journal of Service Industry Management, Vol. 6 No. 4, pp. 20-39.

Lockwood, A. and Jones, P. (1989), "Creating positive service encounters", Cornell Hotel \& Restaurant Administration Quarterly, Vol. 29 No. 4, pp. 44-50.

Mills, P.K. (1990), “On the quality of service in encounters: an agency perspective”, Journal of Business Research, Vol. 20 No. 1, pp. 31-41.

Oliver, R.L. (1993), “A conceptual model of service quality and service satisfaction: compatible goals, different concepts", Advances in Service Marketing and Management, Vol. 2, pp. 65-85.

Parasuraman, A., Zeithaml, V.A. and Berry, L.L. (1988), "SERVQUAL: A multiple-item scale for measuring customer perceptions of service quality”, Journal of Retailing, Vol. 64 No. 1, pp. $12-40$.
Mapping service experience 
BPMJ

5,1

64
Plaia, A. and Carrie A. (1994), "Application and assessment of IDEF3 - process flow description capture method”, International Journal of Operations \& Production Management, Vol. 15 No. 1, pp. 63-73.

Schneider, B. and Bowen, D.E. (1993), "The service organization: human resources management is crucial", Organizational Dynamics, Vol. 21 No. 4, pp. 39-52.

Shostack, G.L. (1984), "Designing services that deliver”, Harvard Business Review, Vol. 6 No. 1, pp. 133-9.

Stafford, M. R. (1994), "How customers perceive service quality”, Journal of Retail Banking, Vol. 16 No. 2, pp. 29-37.

Su, C.J. (1996), Lecture Notes of the Course of BPR, Dept. of IEEM, Hong Kong University of Science and Technology, Hong Kong.

Sulek, J.M., Lind, M.R. and Marucheck, A.S. (1995), "The impact of a customer service intervention and facility design on firm performance”, Management Science, Vol. 41 No. 11, pp. 1763-73.

Woodruff, R.B. (1997), "Customer value: the next source for competitive advantage", Journal of the Academy of Marketing Science, Vol. 25 No. 2, pp. 139-53.

Zeithaml, V.A., Berry, L.L. and Parasuraman A. (1993), "The nature and determinants of customer expectations of service", Journal of the Academy of Marketing Science, Vol. 21 No. 1, pp. 1-12. 